\title{
Research of Sales Contract Management System Based on WEB
}

\author{
Hualun Lai \\ Business School \\ University of Shanghai for Science and Technology \\ Shanghai 200093, China \\ Tel:86-21-5527-1343 E-mail: laihl@usst.edu.cn \\ Liangwei Zhong \\ CAD center \\ University of Shanghai for Science and Technology \\ Shanghai 200093, China \\ Tel:86-21-5527-6487Ｅ-mail: zlv@usst.edu.cn \\ Jing Ni \\ Business School \\ University of Shanghai for Science and Technology \\ Shanghai 200093, China \\ Tel:86-21-5527-1343 E-mail: nijing501@126.com
}

Supported by Shanghai Leading Academic Discipline Project (S30504, J50503) and Shanghai Education Committee (05EZ30)

\begin{abstract}
On the basis of study on information stream of management of contract, a frame of an information system of management of contract with holistic information is designed. Sale and production forecast is put forward in terms of data mining technique and customer management concept and relevant system is developed. System information includes customer management system, elaborate content of contract, finance management in the execution of contract, record of change of contract, control of dispatch process, shares information with packaging system, and also shares information with warehouse management system to realize the control of dispatch process. Data of customers and sale of products information is obtained through data mining of customers and contract information. Good forecast for market can be made by the data which also places perfect basis for the decision of production planning.
\end{abstract}

Keywords: Sell contract, Management system, WEB, Object-Oriented, Whole lifecycle

\section{Introduction}

The sales contract is the important production information of manufacturing firm, it includes the attribute of the user request, specification and delivery time and the information which enterprise formulation and in the execution productive plan process involves. The Manufacturing firm and user's link are connected by it. In the Manufacturing firm, the contract schedule must be formulated between Master Production Schedule and Production Schedule. Contract schedule must guarantee that all duties in the Master Production Schedule are completed and that production schedule arranges well production as schedule in each contract. Contract schedule is the refinement of the Master Production Schedule. To make the enterprise interior operation be Consistent, its function is not only Communication between inside and outside, but also reducing the contradiction and the error between the Sale branch and Production department.

Manufacturing industry enterprise's contract management includes management completed in ERP system and independent management system. The two kinds of systems have some Weaknesses such as incomplete information record, not thorough integrations with other systems and weak analysis ability. It is disadvantageous to enterprise's informationization construction and influences seriously on enterprise market reaction rate and market competition ability, which is more obvious to the large-scale manufacturing companies that have complex products than others.

On the foundation of contract management information flow is studied, contract management information system's 
frame having complete information is designed, and sales and the production forecast method according to the data mining technology and client management's theory is proposed. The corresponding system has been developed. The system core goal is that a transformation to production schedule and job instruction is made, and that market demand is mapped in the manufacturing promptly and accurately to enhances the enterprise' reaction capacity to the market and enterprise's competitive ability.

\section{System function and Structure}

With analysis of operating methods of contract management, the management processes and management content is concluded based on whole lifecycle sales contract management. The structural feature of process is as shown in Figure 1. The functional modules are as follows:

(1) Contract input

Contract information, including customer information, the framework of the contract, a variety of equipment specifications, model, quantity, and special note, and other information involved by contract is input by staffs of sale department.

(2) Customer Management

Users can look for, modify the information of existing customers and add new customer information into system.

\section{(3) System Maintenance}

Including import and export data, backup and recovery, as well as the management of users (user addition, delete, and the rights granted), operated by the system administrator.

(4) Search

The sales can inquiries contract information signed by the sale department, as well as execute-status of contract. The top leaders can inquire information and execute-status of contract of all sale departments

(5) Contract Modify

Sales can modify the mistake contents of contract, such as payment, product name and specification caused by carelessness. But other some contents can not be modified such as contract ID and contract type.

(6) Financial Check

Accountants check the payment details of contract content in the System on basis of original contract. The contract will not continue the execute process without Accountant's agree, and should be modified by the sales of departments. Only if the contract contents match the rules of company, Accountant will verify the contract.

\section{(7) Generation of production plans report}

The Staff of central sale department make an production application based on the actual situation of stock. Technology department make the BOM on the basis of production of application. Manufacture department staffs make the production plan and order play according to the contents of ERP system, and the Manufacture report will be given to factories.

(8) Financial check for delivering product

Accountants will check the delivering devices on the basis of arrived payment of customer.

(9) Generation of the bill of lading

The bill of lading will be generated according to the financial check and actual stock situation.

The system uses technology structure based on Web, and use the MS SQL Server as database. The development language of system is JAVA, and ECLIPSE is as development environment.

Using the Web Service technology will make the System get further more development and third-party application integration. Figure 2 showed as structure of the system. Web Service uses the standard output interface WSDL (Web Service Description Language) serving for the client of internet/ intranet. It will not emphasis on using what technology to get web solutions.

Web Service changes the programming-Oriented conception of WEB application into a service-oriented conception. The most valuable technology is to integrated different model components and different model components. This contract management system using Web Service technology provided technical support for the system integration in the future of the inevitable internal and inter-enterprise.

\section{Management of the Change of Contract Process}

Customers often require that the contract be changed during the execution of the contract, and the change of contract mainly covers the following range: 
Elimination of contract

Increase and decrease of number

Change of equipment type

Change of equipment parameter

Change of transportation means and so on

The different extent of the change would affect the capital of contract as well as the execution of production plan. Effective management of the data from the change provides data source to guarantee the implementation of data mining. Meanwhile, the system attains the change of production cycle according to the change, and the change provides production planning with basis.

Design of Database

A table recording change of contract is designed in database, and following is its structure:

No. of contract; date of change; content of change; reason of change,..

Content of change directly relate to contract in terms of code. After opening the database, relevant content would be modified and be recorded. Reason of change is character field, which elaborately record the reason that customers put forward and provide data processing with data source.

Other Change Management Results from Change of Contract

Change in many other aspects resulting from change of contract mainly affects production plan. System communicates with PDM system, applies for change of design and exports changed data of BOM according to changed data. Generally, there is no change of production planning process. Therefore, it is required that change of production planning as well as changed data of purchasing planning be obtained by change module in production system according to production capacity.

Management module in change of contract process will record data which is created in the process of change of contract in database. Data becomes affluent with the increasing use of system.

\section{The application of Data Mining Technology}

(1) Data Mining System

Data Mining System is an independent three-tier structure. The bottom layer is data, and read data sources from the SQL Server. The middle is mining, and has multi-dimensional database and excavation engine. Top-layer can switch data with user interface.

(2) The realization of Data Mining

(3) Association Rules Mining

Data Mining (Data Mining), refers to mine hidden, useful and not yet found the information and knowledge from a large number of the raw data, is considered an effective method to resolve the current "data rich and information poor". Association Rules Mining is one of important areas of Data Mining (Liu, xin, etc. 2007).

According to different situations association rules can be classified as follows:

a) According to dealing with the types of variables of rules, the association rules can be divided into Boolean and Value type.

b) According to data abstract level of rules, the association rules can be divided into single and multi-association rules.

c) According to relating to the dimensions of the data of rules, the association rules can be divided into one-dimensional and multi-dimensional.

(4) Association Rules Mining Algorithm

From the large-scale database mining association rules require two steps:

a) Finding all the frequent set.

b) Producing strong association rules by the frequent set.

The study of Association Rules Mining focuses on the first step (Li, Shujuan, etc. 2004). The discovery ways of association rules, the most influential algorithm is the Apriori algorithm, which uses a gradual approach called iterative search. The basic algorithm is as follows: firstly, traversing one time to goal database, recording appearance times of each item and attribute. that is, calculating the degree of support for each project to collect project constitutes frequent table-L1which all the support degree is not less than the minimum support degree of user, and then link all the elements right of $\mathrm{L} 1$, form candidate-C2, once again traversing the services database, calculated support degree for each set of 
options of $\mathrm{C} 2$, to collect project constitutes frequent table-L2 which all the support degree is not less than the minimum support degree of user, and then link all the elements right of $\mathrm{L} 2$, form candidate-C3, traversing the services database to get L3, repeatedly implementing the course until the options stopping.

(5) Multi-association Rules Mining device

Apriori algorithm is more complicated, using an improved algorithm of the SDA in the paper, and using this improved algorithm to develop a multi-level association rule mining device, two interrelated can be found in relational association: property correlation and cross-attributes link. The former is a link among different properties; the latter is an inner association of one property or attributes collection, at the same time that the association integrates with another set of attributes or properties (Yang, guang \& Wang, rui. 2007.).

Through the analysis of the data mining system gets the trend of product sales, as well as products associated with the user, the factor weight to the contract changes, the integration of contract change and association of products and users etc..

\section{Integrated with packaging system}

Delivering product is an important part of contract management, the completion of shipments of equipment marks contract completed. Generally, customers will clearly stipulated batches delivering product in a different time in the contract, because of the size of the goods being different, a device may be divided into a number of packing cases, or many devices may be put a pacing case due to the smaller size of the goods.

Delivering product list must be marked information of packing cases, including the number of cases, identification number etc., the information is not included in the contract information and need integrated with packaging system to get product packing information of a contract.

In the database system level system integrates with packaging system, in the packaging systems database has packing case and contract data table, this table will relate with equipment constitute table in contract management, and generate detail data including delivering product list of packing case.

\section{Integrated with financial system and inventory system}

Shipments must meet the requirements of the stock and financial conditions, and to financial the user must pay the money of contract demand before delivering product, to inventory, products must check to inventory before delivering product. The information of inventory and financial needs integrate with inventory system and financial system.

System integrates with financial system and inventory system in the database level, the database in the financial system has detail information of the process of payment of user, and the database in the inventory management system has detail information of products, this table will relate with delivering product control management table in contract management, and strictly control delivering product behavior of products.

\section{Conclusion}

1) Contract management system has closer ties with customer management systems, packaging system, financial system, and inventory management system etc., and easy to integrate with these systems, owing to the system architecture applying B / S system based on WEB.

2) Contract management system using data mining techniques provided the basis for forecasting, and data sources for data mining based on complete record to contract changes.

3) Information of system integrated with financial system and inventory information system reaches purpose of controlling delivering product, and put an end to human error.

\section{References}

Huang, meihua and Zheng, shaohong. (2005). Development and Research of management system based on B/S for Contract and Cost Controlling. COMPUTER AND DIGITAL PROJECT. P64. 2005. Vol. 33. 03.

Li, Shujuan etc. (2004). Development of Contract Management System based on JSP. COMPUTER ENGINEERING. 2004.12.

Liu, xin etc. (2007). The Application Research of Data Mining Algorithms for Intrusion Detection. COMPUTER AND INFORMATION TECHNOLOGY. P92 94. 2007.06.

Liu, Yabin etc. (2005). Master Eclipse. Electronics Industry Press. 2005.

Shi, Weiwei and Feng, Mei. (2007). Conqure JavaScript. Posts \& Telecom Press.

Yang, guang and Wang, rui. (2007). Research of Mining Algorithm based on Association Rules. COMPUTER AND INFORMATION TECHNOLOGY. P46 50.2007. 04. 


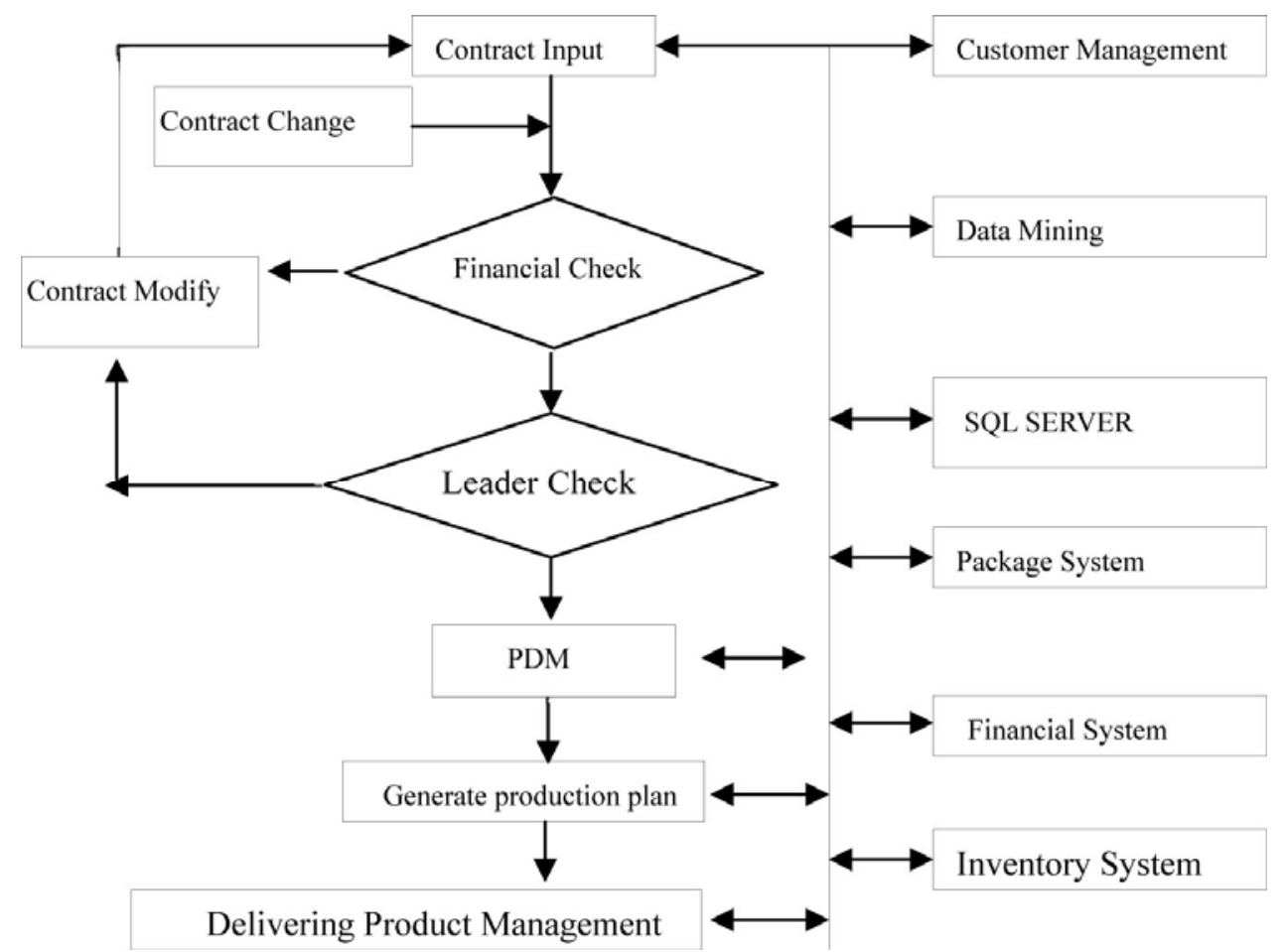

Figure 1. function Structure

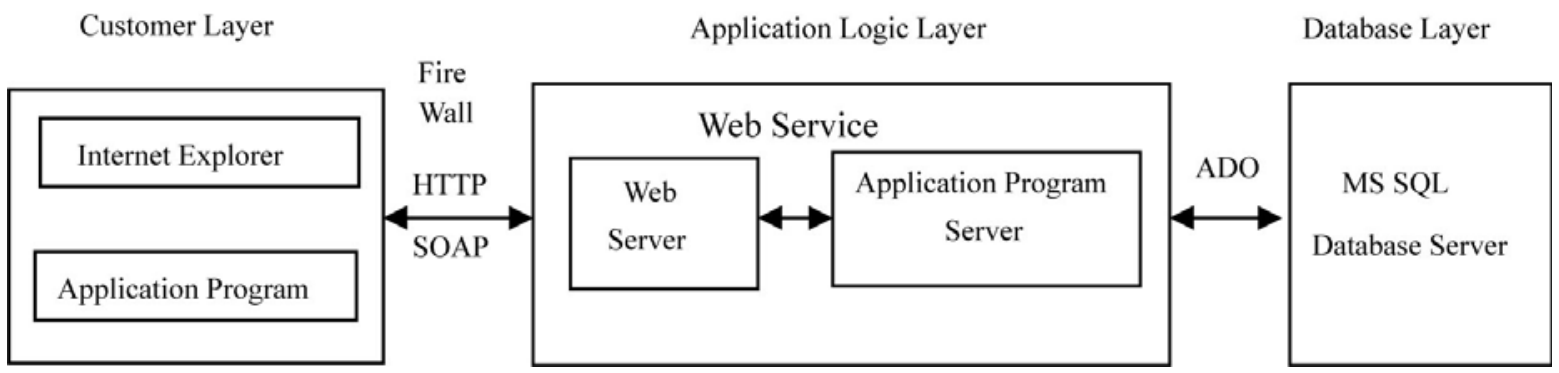

Figure 2. System Structure 